\title{
Utilizing Modular Neural Network for Prediction of Possible Emergencies Locations within Point of Interest of Hajj Pilgrimage
}

\author{
Adamu Abubakar ${ }^{1}$, Haruna Chiroma ${ }^{2}$, Abdullah Khan ${ }^{3}$, Mukhtar Fatihu Hamza ${ }^{4}$, Ali Baba Dauda ${ }^{5}$, Mahmood $^{2}$ \\ Nadeem $^{1}$, Shah Asadullah ${ }^{1}$, Jaafar Zubairu Maitama ${ }^{6} \&$ Tutut Herawan $^{7}$ \\ ${ }^{1}$ Department of Information Systems, International Islamic University Malaysia, Kuala Lumpur, Malaysia \\ ${ }^{2}$ Department of Computer Science, Federal College of Education (Technical), Gombe, Nigeria \\ ${ }^{3}$ Faculty of Information Data Base, Agriculture University Peshawar, Pakistan \\ ${ }^{4}$ Department of Mechatronics Engineering, Bayero University, Kano, Nigeria \\ ${ }^{5}$ ICT Center, University of Maiduguri, Maiduguri, Nigeria \\ ${ }^{6}$ Department of Information Technology, Bayero University Kano, Nigeria \\ ${ }^{7}$ Department of Information Systems, University Malaya, Kuala Lumpur, Malaysia \\ Corespondence: Adamu Abubakar, Department of Information Systems, International Islamic University \\ Malaysia, Kuala Lumpur, Malaysia. Tel: 603-6196-6433. E-mail: adamu@iium.edu.my
}

Received: June 12, 2015

Accepted: November 1, 2015

Online Published: December 24, 2015

doi:10.5539/mas.v10n2p34

URL: http://dx.doi.org/10.5539/mas.v10n2p34

The research is financed by Grant of the Ministry of Education under Foundational Research Grant Scheme (FRGS15-245-0486).

\begin{abstract}
This paper utilize modular neural network for prediction of possible emergencies locations during hajj pilgrimage. Available location, localization and positioning determination systems become increasingly important for use in day-to-day activities. These systems dwells on various scientific tools which ensure that the systems will provide accurate response to the needed service at the right time. Unfortunately, some tools were faced with drawbacks, either their use was not appropriate or they do not give reliable results, or the results obtained in certain scenario might not be apply to other scenarios. For this reasons, we utilize modular neural network tool to examine the analysis of determining possible emergencies locations within point of Interest of Hajj Pilgrimage in Meccah Saudi Arabia. The prediction results are generated by the use of longitude, latitude and distances as the dataset. Modular neural network takes longitude and latitude as inputs and predict distances within pilgrim's possible point of interest. The learning systems were trained on the collected data. Experimental investigation demonstrated that modular network produce higher prediction accuracy compaired to other tools. This finding would contribute to the design of add-on applications which will deem to provide location based services for possible emergencies locations.
\end{abstract}

Keywords: Modular Neural Network, location, localization, positioning determination

\section{Introduction}

\subsection{Background of the Problem}

During Hajj pilgrimage in Mekkah Saudi Arabia, volunteer Doctors from different countries take part as medical team of their own country delegation's of the pilgrims. Most of the Doctors are general practitioners. The doctors sole responsibilities lies in an emergency situation, not treating patients, and if found they are liable for prosecution by the Saudi authorities. Most of the clinic for these foreign doctors during pilgrims in Makkah are set up in hotel rooms and open for most time during Hajj pilgrims. The doctors are always available in Al-haram; the name given to Al-Masjid Al-Haram the grand mosque where the holy Al Ka'ba building is located in center of Mecca, Saudi Arabia. There are 25 gates into the Mosque 8 from the north, 7 from the south, and 5 from the east and 5 from the west respectively. The distance of the holy Al Ka'ba to any gate is approximately 300 meters. In most cases the area of the Mosque is always overcrowded. The crowd situation is some cases sprawl up to $2 \mathrm{KM}$ radius from the 
holy Ka'ba. There are high possibilities of emergency situation by pilgrims. The doctors from any affected delegation might be around with their medical kits. They could be in any point of interest. The possibilities that doctors could be at each point of Interest from the holy ka'ba could be predicted base on the prior knowledge of the point of interest and their distance from the holy Ka'ba. For that reason, this study aimed at exploring information on distance proximity which connects to other point of interest at about 10 kilometers radius from the holy $\mathrm{Al}$ Ka'ba building in order to show how far point of interest are separated from the grand mosque, and predict doctors locations relative to an emergencies situation position, in order to get doctors of close proximity to the point of emergencies. Hotels, malls, and almost the entire area $2 \mathrm{~km}$ radius from Ka'ba are among the most important pilgrims point of interest.

Points of interest are key locations that when trying to predict position of an emergencies situation might require the attention of the closet medical doctors. People may have some choices based on specifies distance computed by the time it takes to move from point A to point B over the path generated by location facts, beliefs and experience of moving from one area to another. That is why there is point of interest. People always know where they are, and will always notice objects or location intended to visit in mind. However, individuals on the move do not notice distance in respect to their path than they do in respect of time for a short or long distance.

Going for pilgrimage somewhere else by pilgrims is associated with the perception of visiting ritual sites which could be one or many places and the distance apart from either one ritual site to the other or from pilgrim's accommodation to ritual sites and other places of visit are important to the visiting pilgrim's. Pilgrimage is a trip made to places with the purpose of worshiping in order to discharge some religious obligation by Christians, Hindus, Buddhists, Baha'is, Muslims etc, the assumption is that any person who travel for performing pilgrimage generally is willing to go to all the ritual sites regardless of distance between the rituals sides. The mode of transportation to the ritual sites is by car, ship, train, bus, lorry, or even by walk. No matter what the distance may be, pilgrimages have no alternatives. This typical scenario is observed in Mecca Saudi Arabia during Muslims pilgrimage. Going to Mecca in Saudi Arabia for performing hajj at least once during lifetime is the fifth pillar of Islam and one of the Muslim's duties which display the most significant manifestation of Islamic faith and unity with over 2.5 million people expected from all over the world annually. It is recommended for Hajj pilgrims to be in a holy $\mathrm{Al} \mathrm{Ka'bah,} \mathrm{Mina,} \mathrm{Mudzalifah} \mathrm{and} \mathrm{Arafat} \mathrm{at} \mathrm{the} \mathrm{right} \mathrm{time} \mathrm{when} \mathrm{performing} \mathrm{hajj.} \mathrm{However,} \mathrm{the} \mathrm{proximity}$ of these locations to other point of interest is beneficial to hajj pilgrims in order to schedule visiting other places. Most hajj pilgrim during the hajj rituals prefer to walk due to the nature of crowd and the road networks. It's hard to reason how far hajj pilgrims will prefer to walk to the ritual sites (holy Al Ka'bah and other sites). The walk distances are graph-geodetic and converge to the shortest path distance while a long walk distance is described as approaching limit values which a person cannot withstand, thus the long walk distance is equal to the resistance distance (Pavell, 2012). It is important to provide actual distance proximities not based on roads network alone, but also including the entire pedestrian route to all possible point of interest within the principal ritual site (holy $\mathrm{Al}$ Ka'bah).

The focus of this paper is to apply modular network to built models for predicting locations of possible emergencies cases. Computational foundation of neural networks research was spring up by McCulloch and Pitts in the early 40's, details can be found in (Sharkey et al., 2000). There are numerous works in literature on comparing prediction performances of different architectural configurations of neural networks referred to as learning method in (Granitto et al., 2005). Feed forward neural networks are better than other architectures in terms of pattern recognition (Bishop, 2006). In Gencay and Liu (1997), feed forward and recurrent network were compared. Support vector machine and back propagation neural network were contrasted in (Cao \& Tay, 2001; Tay \& Cao, 2001). Recurrent network and multilayer feed forward neural network compared in (Kulkarni \& Haidar, 2009). Time delay, recurrent and probabilistic neural networks compared in (Saad, 1998). Comparison of neural network and support vector machine is presented in (Fernandez, 2012). Multilayer perceptron feed forward neural network, recurrent neural network and Elman recurrent networks were compared in (Quek et al., 2008). Support vector machine and back-propagation neural network were contrasted in (Xie et al., 2008). Neuro-fuzzy inference system, multi-layer perceptron and radial basis function networks compared in Kaynar et al., 2010). Elman networks, feed forward neural network and adaptive neuro-fuzzy inference system compared in (Zimberg, 2008). Conventional support vector machine and improved cluster support vector machine contrasted in (Qi \& Zhang, 2009). Back-propagation neural network, support vector machine regression and radial basis function neural network contrasted in (Yu et al., 2008). Multilayer feed forward network and support vector machine contrasted in (Byvatov et al., 2003). Finally, study in (Chen et al., 2011) compared support vector regression and radial basis function network. Results of these comparisons are presented in Table 11. There is lack of check for statistical significance difference in prediction performances among compared neural networks architectures. In this paper, 
we experimentally investigate prediction performances of modular network in contrast to support vector machine within the context of distance prediction of location. We step further and check for correlation between values predicted by the two models. Lastly, we check whether there is statistical significance difference between prediction accuracy of the two models?

\subsection{Modular Neural Network}

Modular network was pioneered in (Jacobs et al., 1991). Committee machines are class of artificial neural network architecture that uses the idea of divide and conquer. In this technique, larger problems are partition into smaller manageable units easy to be solved and the solutions obtained from various units are recombined once more to have a complete solution to the problem. Therefore, a committee machine is a group of learning machines refers to as experts in which their results are integrated to yield an optimum solution better than solution of individual expert. Learning speed of modular network is superior to other class of neural networks when compared (Lopes et al., 2004). Individual output of each sub-network in modular network are modulated by gating sub-network to yield only one output of modular network as shown in Figure 1, gating sub network is responsible for assigning each expert network to suitable sub regions of the input space (Funand \& Hagan, 1996). Learning of patterns is competed among experts and gating network serves as the competition mediator (Jacobs \& Jordan, 1993). Therefore, output of the committee machine is determined by the gating unit (Sheikhan \& Ali, 2012). There is another class of modular network without gating, where outputs of all experts are linearly combined (ensemble averaging) to produce one single output of the network as depicted in Figure 2. The gate values ranging from 1 to 0 are multiply with experts output so as to select the most highly relevant output. Struggle for selection among experts become tougher if gating value is either 1 or 0 otherwise "a certain degree of blending between the module outputs ensues, which is of particular interest in smoothing out the final result around the borders of the partition of the training data." (Carcenac, 2008). The modular network in Figure 1 have output as follows

$$
y=\sum_{i=1}^{N} g_{i} y_{i}
$$

where $y=$ sum of modular network output.

$y_{i}=$ output of expert $i$.

$g_{i}=i$ th output gating subnetworks.

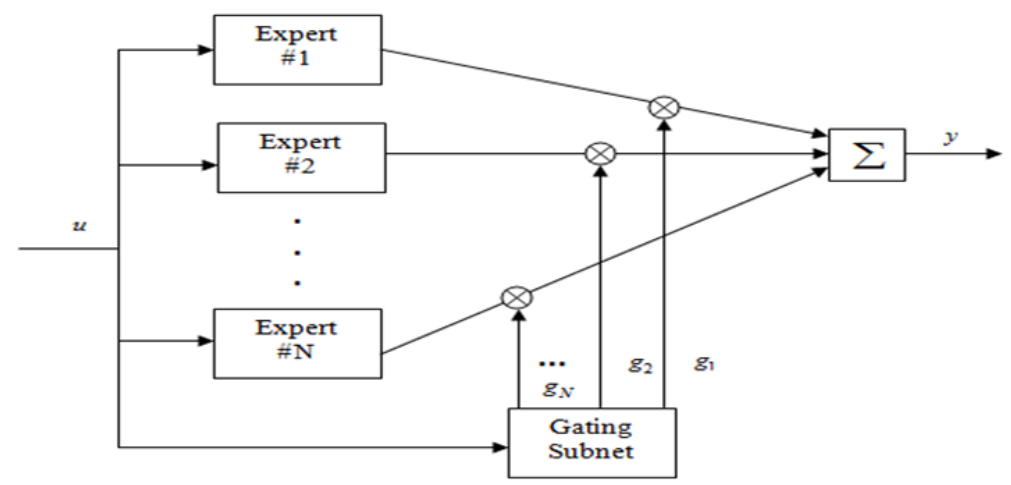

Figure 1. Committee Machine

Each expert is having multilayer network with varying configurations. Gating subnet may have a multiple network with soft-max activation function $\left(g_{i}\right)$ at the last layer.

$$
g_{i}=\frac{\ell^{s_{i}}}{\sum_{j=1}^{N} \ell^{s_{j}}}
$$


where $S_{i}=$ network input to the transfer function at the last layer. Substituting Equation 2 in Equation 1, then we have Equation 3 as follow

$$
y=\sum_{i=1}^{N}\left(\frac{\ell^{s_{i}}}{\sum_{j=1}^{N} \ell^{s_{j}}}\right) y_{i} .
$$

Modular network performance index is given by

$$
J(X)=\ln \sum_{i=1}^{N} g_{i} \ell^{-\frac{1}{2}\left(y^{*}-y_{i}\right)^{T}\left(y^{*}-y_{i}\right)} .
$$

Substituting Equation 2 in Equation 4 we have Equation 5

$$
\begin{gathered}
J(X)=\frac{\ell^{s_{i}}}{\sum_{j=1}^{N} \ell^{s_{j}}}\left[\ln \sum_{i=1}^{N} g_{i} \ell^{-\frac{1}{2}\left(y^{*}-y_{i}\right)^{T}\left(y^{*}-y_{i}\right)}\right] \\
X=\left[r_{1} r_{2}, \cdots, r_{N} Z\right]^{T},
\end{gathered}
$$

Where $r_{j}=$ parameter vector comprising weights and biases in the $j$-th expert sub-network. $\mathrm{Z}=$ vector comprising weights and biases of gating sub-network. $y^{*}=$ desired output vector as given in (Funand \& Hagan, 1996).

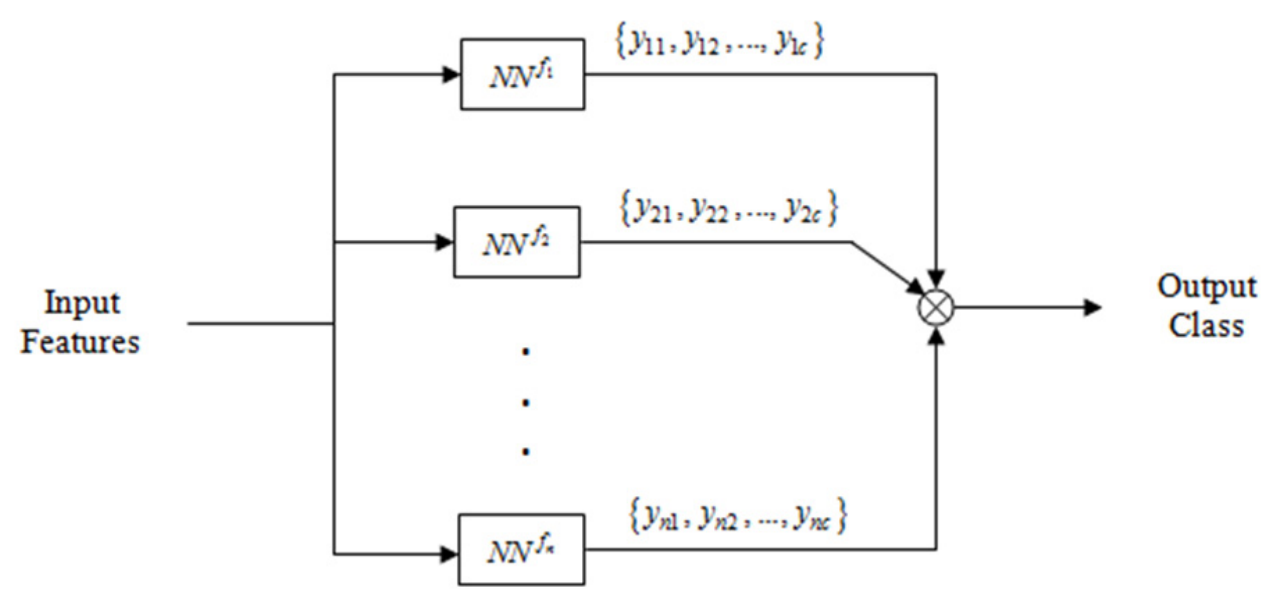

Figure 2. Modula neural networks without gating (Cho, 1997)

Gradient based algorithms are typically used to train modular network as pointed out in (Jacobs \& Jordan, 1993). Performance index is minimized by network training and steepest ascent algorithms technique is the easier way to achieve it.

$$
x_{k+1}=x_{k}+\alpha \frac{\partial j}{\partial x}
$$

Computation of gradient is realized by computing partial derivative of Equation 7 with respect to network input of gating sub-network at the last layer. 


$$
\frac{\partial j}{\partial s_{i}}=h_{i}-g_{i},
$$

where

$$
h_{i}=\frac{g_{i} \ell^{-\frac{1}{2}\left(y^{*}-y_{i}\right)^{T}\left(y^{*}-y_{i}\right)}}{\sum_{j=1}^{N} g_{j} \ell^{-\frac{1}{2}\left(y^{*}-y_{j}\right)^{T}\left(y^{*}-y_{j}\right)}} .
$$

Substitute Equation 2 and Equation 9 in Equation 8 to get Equation 10 as follow

$$
\frac{\partial j}{\partial s_{i}}=\frac{g_{i} \ell^{-\frac{1}{2}\left(y^{*}-y_{i}\right)^{T}\left(y^{*}-y_{i}\right)}}{\sum_{j=1}^{N} g_{j} \ell^{-\frac{1}{2}\left(y^{*}-y_{j}\right)^{T}\left(y^{*}-y_{j}\right)}}-\frac{\ell^{s_{i}}}{\sum_{j=1}^{N} \ell^{s_{j}}} .
$$

- $\quad$ Computation of $j$-derivative with respect to weights in getting sub-network ( $\mathrm{Z}$ )

- Combine Equation 10 with $\frac{\partial s}{\partial z}$, standard back-propagation technique can be used for the computation.

- Compute derivative of $j$ with respect to weights in expert sub-networks, $r_{i}$ in this case there is the need for computation of $j$ derivative with respect to expert sub-networks outputs.

$$
\frac{\partial J}{\partial y_{i}}=h_{i}\left(y^{*}-y_{i}\right)
$$

Combination of Equation 11 with $d y_{i} / d r_{i}$ yields derivative of $j$ with respect to weights in the expert sub-network. Back-propagation may be used for the computation (Jacobs \& Jordan, 1993). Modular network provide alternative solution to problem of local minima normally experience by back propagation learning (Ishikawa, 1995). Modular network has been used for image transformation (Carcenac, 2008), fault diagnosis (Sheikhan \& Ali, 2012), motion adaptive de-interlacing (Choi \& Lee, 2011), prediction (Gradojevic et al., 2009), pattern recognition (Martinez et al., 2005), image processing (Srivastava et al., 2012) and classification (Anand et al., 2005).

\section{Method}

\subsection{Dataset}

The geographical distance between two or more locations measured along the surface of earth is usually obtained by considering each point as a geographic coordinate namely longitude and latitude. Longitude and Latitude are imaginary lines on earth which runs from east to west and north to south respectively, measure in angular degrees. Longitude is measure at an angle east or west from the Prime Meridian, ranging from $0^{\circ}$ (refers to as Prime Meridian) to $+180^{\circ}$ eastward and $-180^{\circ}$ westward, while Latitude ranges from $0^{\circ}$ ( refers to as the Equator) to $90^{\circ}$ north or south (refers to as poles). In geodesy and geophysics, data of global coverage are often given on a latitudelongitude grid of constant intervals in latitude and longitude called the gridded data, or referred to as spherical harmonic expansion (Guo \& Shum, 2009).

A map projection transforms the Earth's spherical two-dimensional coordinate system to the plane or planimetric map surface. Throughout history, map projections have been developed to meet various mapping purposes (Kessler, F. C., 2009). The current availability of global positioning systems (GPS) that can rapidly and accurately determine latitude-longitude coordinates has the potential to produce large amounts of position data that may need to be plotted on a variety of map projections (Allison, 2005; Kaplan \& Hegarty, 2006). The GPS system was developed by the U.S. Department of Defense under its NAVSTAR satellite program (Grewal et al., 2001). The GPS is a satellite-based radio-navigation system emitting special coded satellite signals that can be processed in a GPS receiver. This enables the receiver to compute position, velocity, and time. The system provides accurate, continuous, worldwide, three-dimensional position and velocity information to any user with the appropriate receiving equipment. It is also the source of coordinated universal time. The satellite constellation nominally 
consists of 24 satellites arranged in six orbital planes with four satellites each. A worldwide ground control network monitors the condition and status of the satellites. This network also uploads navigation data and other data to the satellites. Normally, four GPS satellite signals are used to compute positions in three dimensions (latitude, longitude, altitude), and the time offset in the receiver clock. As a result, the GPS system has become prominent for providing navigation information for military and civilian applications in land vehicles, marine vessels, air transport, life safety, and many others (Wang et al., 2009). Most importantly, GPS can provide services to an unlimited number of users (Abubakar et al., 2011) whose role is limited to that of passive receivers. The system utilizes the concept of one-way time of arrival ranging. Satellite transmissions are referenced to highly accurate atomic frequency standards on board the satellites, which are in synchronism with a GPS time base.

Unfortunately the system does not provide information on distances between different locations on earth. The idea of calculating distance on earth surface deals with the science of measuring the structure and size of the earth (Geodesy) and the notion of either flat-earth, Spherical and Ellipsoidal earth. The distance between points flat-earth model for instance when given two points $\left(A_{1}, B_{1}\right)$ and $\left(A_{2}, B_{2}\right)$ within any place on earth the distance $d$ between these points is given by

$$
d=\sqrt{\left(A_{2}-A_{1}\right)^{2}+\left(B_{2}-B_{1}\right)^{2}} .
$$

Pythagorean Theorem proves that the length of the third side (hypotenuse of right triangle) is sum of two other sides. In this case, the assumption is accurate and will apply to the flat-earth distance between two points when the lengths between the locations (a degree of longitude and latitude) are for short moderate distances (Ericksen, 2007). However, considering the ellipsoid/spherical shape of the earth, the distance between two locations cannot be accurate if Equation 34 is used; rather Vincenty's formulae, law of cosines or haversine formula is more reliable because the distances between two points based on the spheroid structure of the earth is a special case of a more general spherical trigonometry. Therefore, given two longitude and latitude positions within any place, their distances will be evaluated using haversine formula (Robusto, 1957) as follows:

Let the longitude of two points (lon1 and lon2) be: dlon $=\operatorname{lon} 2-\operatorname{lon} 1$

Let the latitude of two points (lat1 and lat2) be: dlat = lat 2 - lat 1

The haversine formula is given by:

$$
a=\sin ^{2}(\text { dlat } / 2)+\cos (\text { lat } 1) \times \cos (\text { lat } 2) \times \sin ^{2}(\text { dlon } / 2)
$$

The great circle distance in radians is given by

$$
c=2 \times a \tan 2(\sqrt{a}, \sqrt{(1-a)})
$$

While the lengths (distance) of degree of longitude and latitude is given as

$$
d=R \times c
$$

Table 1. Group 1, locations that are 300 meters away from the Al Ka'bah building but less than 1 kilometer to pilgrim's point of interest

\begin{tabular}{lccc}
\hline Name & Distance(km) & Latitude & Longitude \\
\hline Al-Ka`bah & 0.32 & 21.423056 & 39.826389 \\
La-Mecque & 0.48 & 21.426666 & 39.826111 \\
Al-Qushashiyah & 0.48 & 21.425556 & 39.828609 \\
Bi'r-Zamzam & 0.80 & 21.424168 & 39.831665 \\
Makkah & 0.80 & 21.420000 & 39.830002 \\
Al-Qararah & 0.97 & 21.428888 & 39.828056 \\
Ash-Shubaykah & 0.96 & 21.420555 & 39.821110 \\
Jadat-al-Bab & 0.95 & 21.424168 & 39.819443 \\
Suq-al-Layl & 0.96 & 21.427221 & 39.833611 \\
Ash-Shamiyah & 0.97 & 21.429445 & 39.823055 \\
An-Naqa & 0.99 & 21.430555 & 39.826111 \\
\hline
\end{tabular}

Where $d$ the distance in kilometers between the two points, $R$ is the mean radius of the earth (6371) and $c$ is the 
great circle distance in radians (Sinnott, 1984; Van Liere, 2010; Friedman et al., 2012).

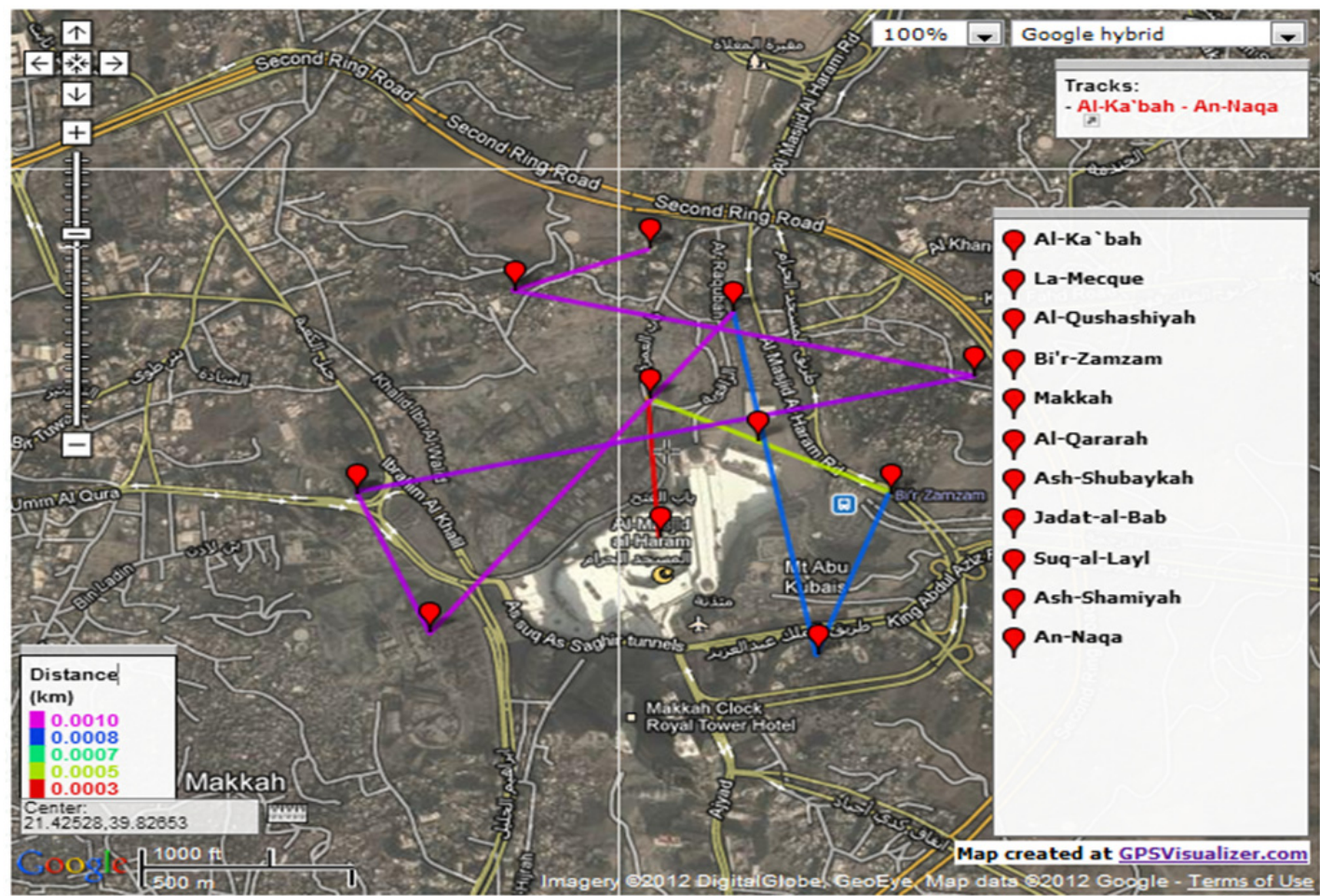

Figure 3. Group 1, locations that are 300 meters away from the kabah building but less than 1 kilometer to pilgrim's point of interest

Data were collected from the municipality situated around $10 \mathrm{~km}$ radius from the holy $\mathrm{Al} \mathrm{Ka}$ 'bah as shown in Figure 6, which indicates some randomly selected points around the holy $\mathrm{Al} \mathrm{Ka}$ 'bah, some of which are the locations required to be known by hajj pilgrims for performing hajj and umrah. These locations (see Figures 3-8) are drawn using GPS Visualizer, an online platform for drawing maps from Google map for any place on the earth. There are three important locations which is obligatory for hajj pilgrims to visits in the holy Al Ka'bah's surroundings which include: Al Ka'bah building, for performing Tawaf; Safa, the hill on which the hajj pilgrim begins his/her walking is about 200 meters southeast of Al ka'bah building; Marwa the hill on which hajj pilgrim end his/her walking is about 250 meters northeast of kabah building and the well of ZamZam for drinking ZamZam water, is about 150 meters southeast of $\mathrm{Al} \mathrm{Ka'bah} \mathrm{building.} \mathrm{(Note} \mathrm{1)}$

Table 2. Group 2, locations that are 300 meters away from the Al Ka'bah building but less than 3 kilometers to pilgrim's point of interest

\begin{tabular}{lrcc}
\hline Name & Distance (KM) & Latitude & Longitude \\
\hline Al-Ka`bah & 0.32 & 21.423056 & 39.826389 \\
Al-Masfalah & 1.8 & 21.415556 & 39.821945 \\
Ajyad & 1.8 & 21.420279 & 39.836666 \\
Shi'b`Amir & 2.1 & 21.433611 & 39.834721 \\
Jarwal & 2.2 & 21.432777 & 39.818611 \\
Sha`b`Amir & 2.2 & 21.433611 & 39.834721 \\
At-Tundubawi & 2.3 & 21.417223 & 39.814724 \\
As-Sulaymaniyah & 2.9 & 21.438889 & 39.827778 \\
\hline
\end{tabular}




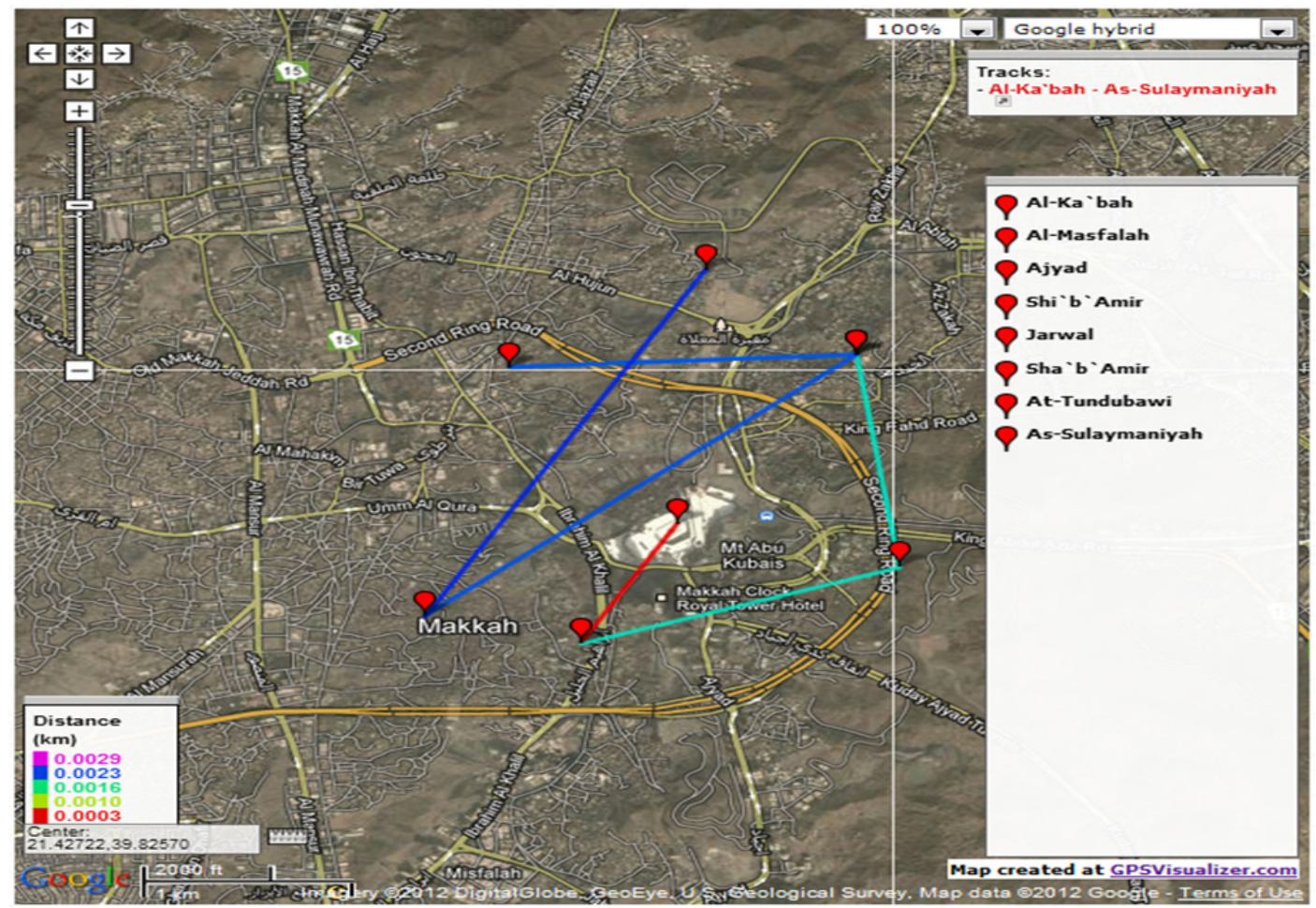

Figure 4. Group 2, locations that are 300 meters away from the $\mathrm{Al}$ ka'bah building but less than 3 kilometer to pilgrim's point of interest

Table 3. Group 3, locations that are 300 meters away from the Al Ka'bah building but less than 5 kilometer to pilgrim's point of interest

\begin{tabular}{lccc}
\hline Name & Distance (KM) & Latitude & Longitude \\
\hline Al-Ka'bah & 0.32 & 21.423056 & 39.826389 \\
AlJummayzah & 3.4 & 21.441389 & 39.834721 \\
Al'Utaybiyah & 3.7 & 21.443890 & 39.826946 \\
Ar-Rawdah & 3.9 & 21.436666 & 39.845554 \\
Al-Hijun & 4.2 & 21.444723 & 39.815834 \\
Al-Faysaliyah & 4.2 & 21.428888 & 39.851387 \\
Jabal-Khandama & 4.3 & 21.401945 & 39.839722 \\
Az-Zahra & 4.7 & 21.431110 & 39.800556 \\
Al-Hindawiyah & 4.7 & 21.419167 & 39.799168 \\
\hline
\end{tabular}

Other important locations that are required to be visited by the hajj pilgrims in order to complete the hajj obligations are outside the holy Al Ka'bah environment, which include Mina, about 9.6 kilometers from the holy Al Ka'bah, Muzdalifa, about 10.1 kilometers from holy Al Ka'bah, and mount Arafat about 23 kilometers from the holy Al Ka'bah. However, for the purpose of this research, randomly selected locations within 10 kilometers radius of the holy Al Ka'bah environment are collected. The distances for each point were obtained base on road network distances. Locations were retrieved in groups, group 1 are these locations situated 300 meters away from the Al Ka'bah building but less than 1 kilometer as shown in Table 1, Figure 3. Group 2 are these locations situated 300 meters away from the $\mathrm{Al} \mathrm{Ka}$ 'bah building but less than 3 kilometers as shown in Table 2, Figure 4. Group 3 are these locations situated 300 meters away from the $\mathrm{Al} \mathrm{Ka'bah} \mathrm{building} \mathrm{but} \mathrm{less} \mathrm{than} 5$ kilometers as shown in Table 3, Figure 5. Group 4 are these locations situated 300 meters away from the Kabah building but less than 6.4 kilometers as shown in Table 4, Figure 6. Group 5 are locations situated 300 meters away from the $\mathrm{Al} \mathrm{Ka'bah}$ building but less than 8 kilometer to pilgrim's point of interest as shown in Table 5, Figure 7 and finally Group 6 are locations situated 300 meters away from the $\mathrm{Al} \mathrm{Ka}$ 'bah building but less than 10.1 kilometer to pilgrim's point of interest as shown in Table 6, Figure 8. 


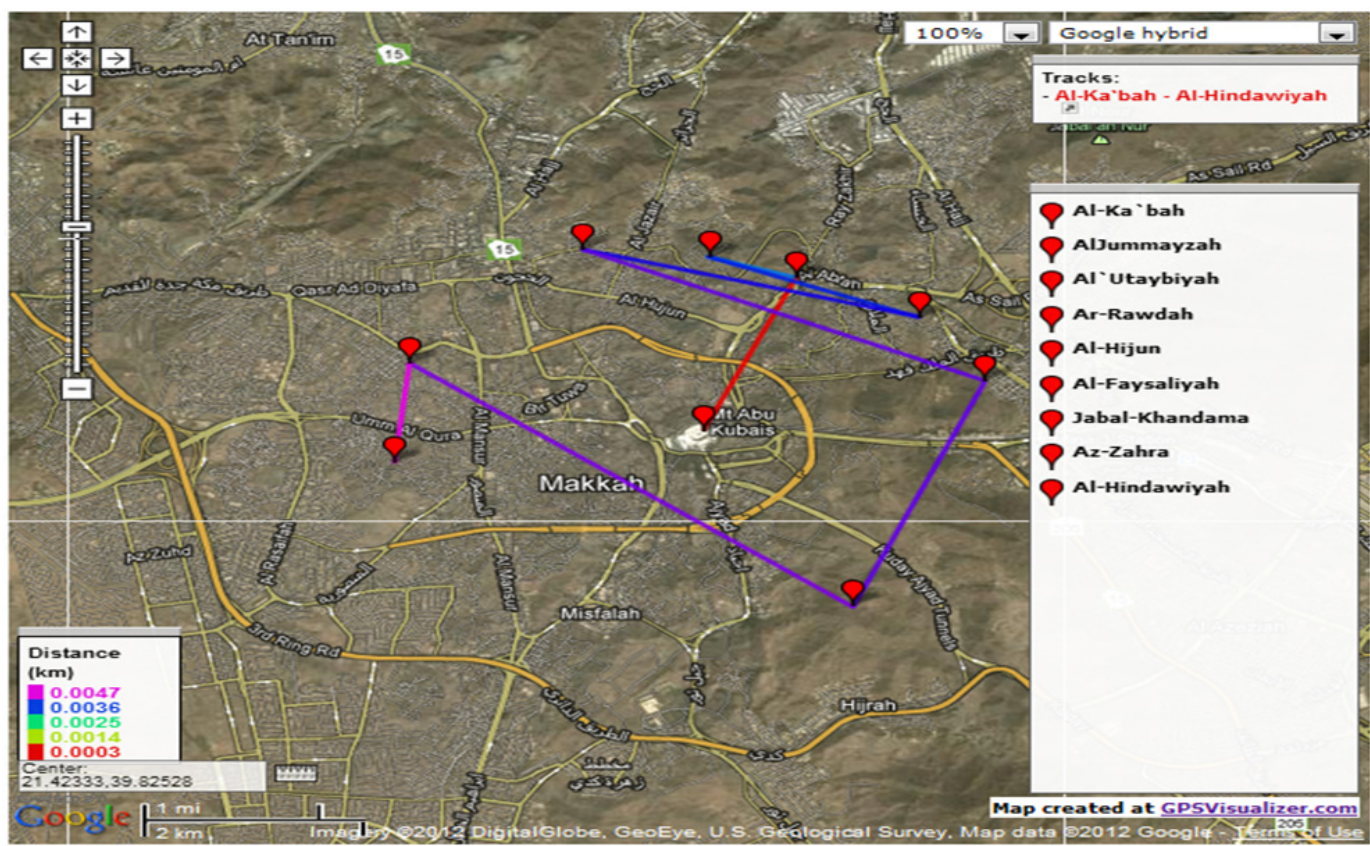

Figure 5. Group 3, locations that are 300 meters away from the $\mathrm{Al} \mathrm{Ka'bah} \mathrm{building} \mathrm{but} \mathrm{less} \mathrm{than} 5$ kilometers to pilgrim's point of interest

Table 4. Group 4, locations that are 300 meters away from the $\mathrm{Al} \mathrm{Ka'bah} \mathrm{building} \mathrm{but} \mathrm{less} \mathrm{than} 6.4$ kilometers to pilgrim's point of interest

\begin{tabular}{lccc}
\hline Name & Distance (KM) & Latitude & Longitude \\
\hline Al-Ka 'bah & 0.32 & 21.423056 & 39.826389 \\
Jabal-Qaws-anNikashah & 5.0 & 21.396389 & 39.819168 \\
Marwa & 5.0 & 21.450001 & 39.816666 \\
Al-Khansak & 5.1 & 21.426390 & 39.858612 \\
Al-Badr & 6.0 & 21.392500 & 39.840557 \\
Al Adl & 6.0 & 21.443611 & 39.856110 \\
Al-Ma`abidah & 6.3 & 21.449722 & 39.852222 \\
\hline
\end{tabular}




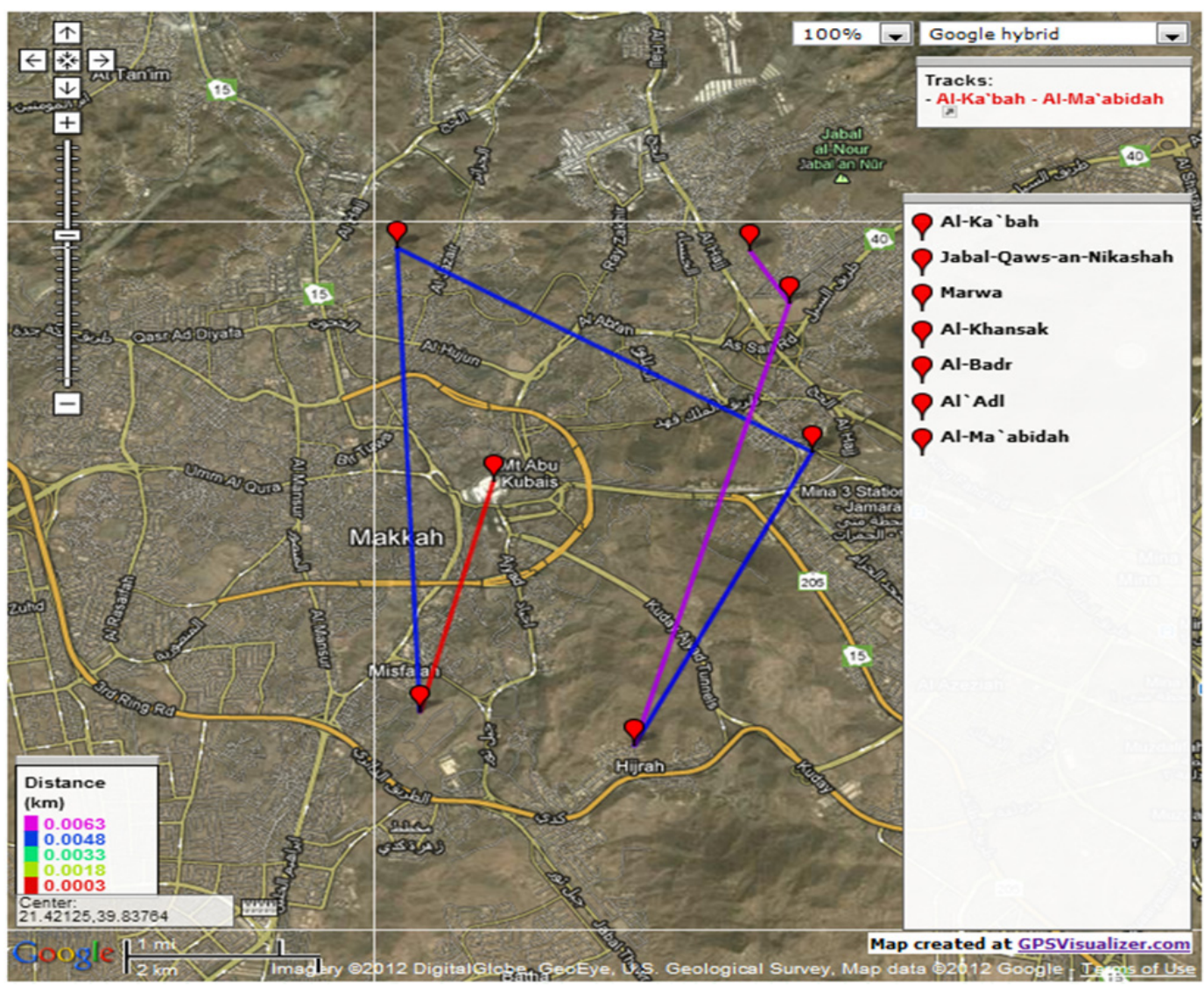

Figure 6. Group 4, locations that are 300 meters away from the $\mathrm{Al} \mathrm{Ka'bah} \mathrm{building} \mathrm{but} \mathrm{less} \mathrm{than} 7$ kilometers to pilgrim's point of interest

Table 5. Group 5, locations that are 300 meters away from the Al Ka'bah building but less than 8 kilometers to pilgrim's point of interest

\begin{tabular}{lccc}
\hline Name & Distance (KM) & Latitude & Longitude \\
\hline Al Ka bah, & 0.32 & 21.423056 & 39.826389 \\
Az Zahir & 6.4 & 21.449444 & 39.801109 \\
Mahgar Elkabch & 6.8 & 21.416666 & 39.866665 \\
Ar Rusayfah & 6.8 & 21.414722 & 39.787498 \\
Ash Shuhada & 6.8 & 21.456667 & 39.808613 \\
Ar Rasifah & 6.8 & 21.414722 & 39.787498 \\
An Nuzhah & 6.8 & 21.431389 & 39.786667 \\
Jami at Umm al Qura & 6.8 & 21.407223 & 39.867500 \\
An Nikashah & 7.7 & 21.385555 & 39.803612 \\
\hline
\end{tabular}




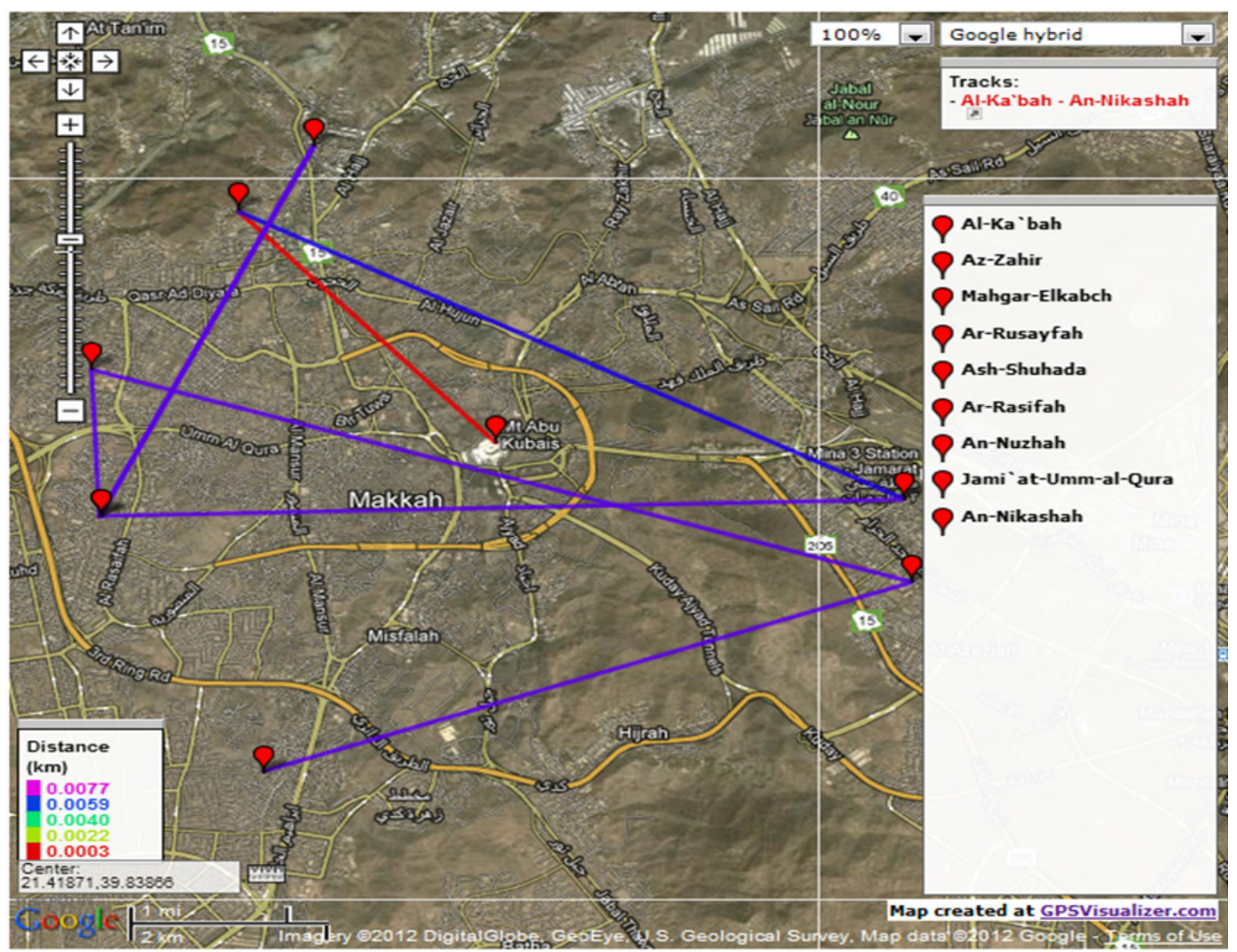

Figure 7. Group 5, locations that are 300 meters away from the Al Ka'bah building but less than 8 kilometers to pilgrim's point of interest

Table 6. Group 6, locations that are 300 meters away from the $\mathrm{Al} \mathrm{Ka'bah} \mathrm{building} \mathrm{but} \mathrm{less} \mathrm{than} 9.9$ kilometers to pilgrim's point of interest

\begin{tabular}{lccc}
\hline Name & Distance (KM) & Latitude & Longitude \\
\hline Al Ka bah & 0.32 & 21.423056 & 39.826389 \\
Umm al Jud, & 8.0 & 21.449444 & 39.787777 \\
Jabal an Nur & 8.2 & 21.458055 & 39.861389 \\
Jabal Thugbah & 8.2 & 21.436945 & 39.875278 \\
As Safra & 8.2 & 21.468056 & 39.839169 \\
Al Aziziyah & 8.2 & 21.403055 & 39.871944 \\
Al Iskan & 8.2 & 21.394167 & 39.788334 \\
Wadi al Jalil & 8.2 & 21.462500 & 39.855000 \\
Gabal Alnoor & 8.2 & 21.458055 & 39.861389 \\
Jabal as Sarid, & 8.5 & 21.376944, & 39.818054 \\
Al Hamra, & 8.9 & 21.428055 & 39.774445 \\
Al Ghassalah & 9.0 & 21.448055 & 39.875000 \\
Jabal Thawr & 9.3 & 21.376667 & 39.851112 \\
Suq al Hatab & 9.3 & 21.375278, & 39.806946 \\
As Sifyani, & 9.7 & 21.475555 & 39.843056 \\
Jabal al Quways & 9.8 & 21.432222, & 39.884998 \\
Bi'r Umm ad Dud, & 10 & 21.433332 & 39.766666 \\
\hline
\end{tabular}




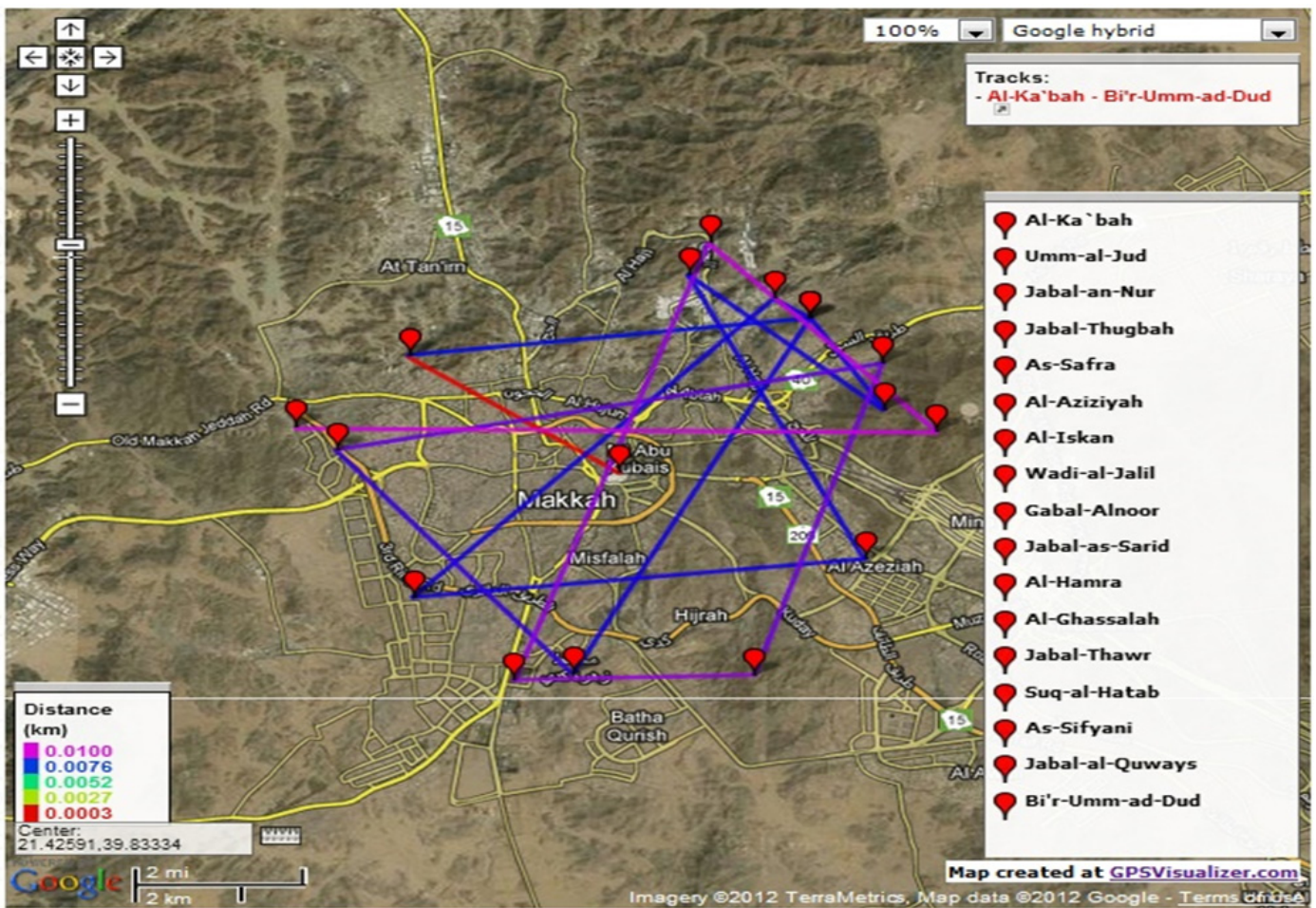

Figure 8. Group 6, locations that are 300 meters away from the $\mathrm{Al} \mathrm{Ka'bah} \mathrm{building} \mathrm{but} \mathrm{less} \mathrm{than} 9.9$ kilometers to pilgrim's point of interest

\subsection{Experiment}

The longitude, latitude and distances collected (see Tables 1-6) from Al Ka'ba to several pilgrim's points of interest in Mecca are grouped together and used for building modular network and support vector machine model in our experiments. In The present work, experiments are conducted in two phases: in first phase data was not normalized and randomized. Second phase data was not normalized but randomized.

The raw data was randomized to improve prediction performance of our models. Experiments were repeated with the randomized data in which data partition ratio (training: cross validation: testing), number of epochs, transfer functions, learning rule and other model configurations used in the first phase of th experiments are maintained in this second phase. Figure 9-10 reported training results for modular network and support vector machine. To ensure good generalization ability of a model, data set which the models have never seen was reserved for testing performance ability. The part of data to be reserved for testing has to be a section of a data in the target population. In this experiment, $25 \%$ (15) of our target data was reserved for testing generalization ability in terms of predicting distances from $\mathrm{Al} \mathrm{Ka'ba} \mathrm{to} \mathrm{point} \mathrm{of} \mathrm{interest} \mathrm{within} \mathrm{Al} \mathrm{Haram}$. The reserved data was executed on modular network and support vector machine. Figure 11 and Table 7 present simulated results.

\section{Results}

This section presented training results of modular network and support vector machine models. The results of the study suggest the effect of both algorithm on efficiency and proficiency of prediction. The error in the training set are drastically decreasing as a function of training set as indicated in Figures 9-10 and the straight lines in both Figures indicated convergence. From Figure 9, the minimum and final MSE during in sample simulation (training) is $6.63 \mathrm{E}-05$ and $6.68 \mathrm{E}-05$ respectively at epoch 152 . Minimum and final MSE of cross validation during hold out are 0.001849 and 0.002198 respectively at epoch of 53 . 


\section{MSE versus Epoch}

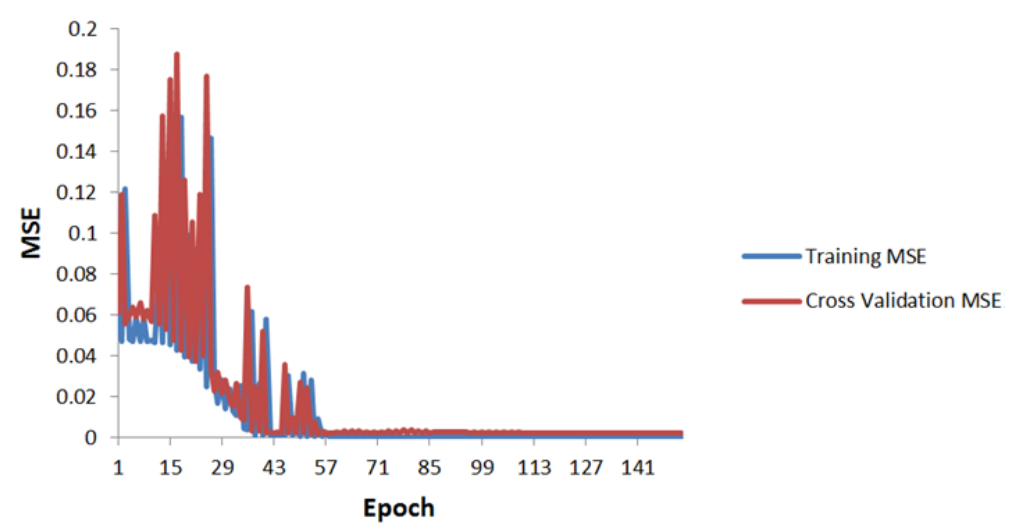

Figure 9. Plot of training and cross validation MSE versus epoch for modular network

From Figure 10, the minimum and final MSE during in sample simulation (training) are 0.041865 and 0.077334 respectively, at epoch of 63. Minimum and final MSE of cross validation during hold out are 0.085142 and 0.086398 respectively at epoch of 306 .

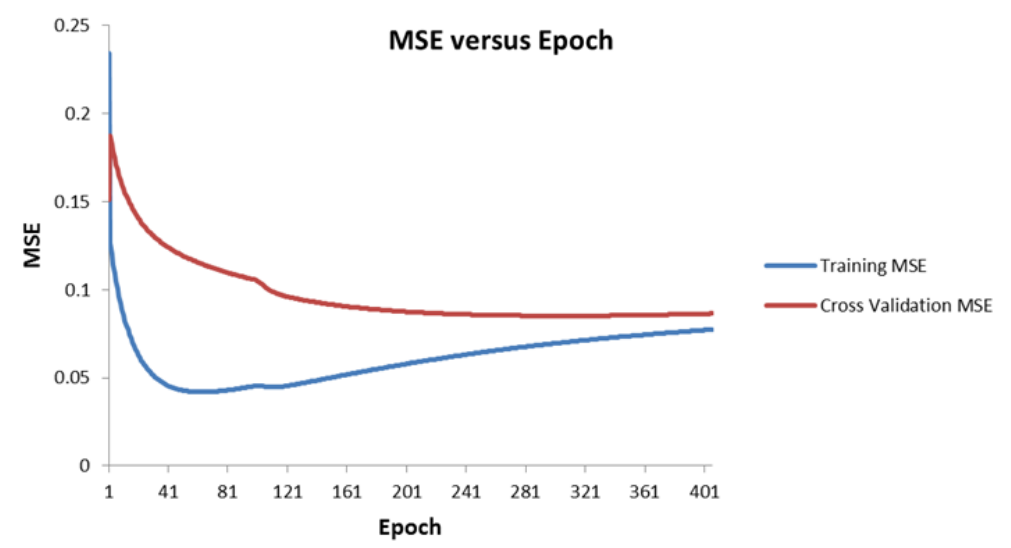

Figure 10. Plot of training and cross validation MSE versus epoch for support vector machine

The data reserved for testing our models are used on modular network and support vector machine. Figure 11 is a plot of distances predicted by both models and actual distances. Table 7 reported performance effectiveness of each model.

Table 7. Performance metrics for modular network and support vector machine

\begin{tabular}{ccccc}
\hline \multicolumn{5}{c}{ Performance measures } \\
\hline & MSE & NMSE & MAE & r \\
\hline MN & 0.803 & 0.073 & 0.686 & 0.963 \\
SVM & 5.073 & 0.459 & 1.744 & 0.868 \\
\hline
\end{tabular}




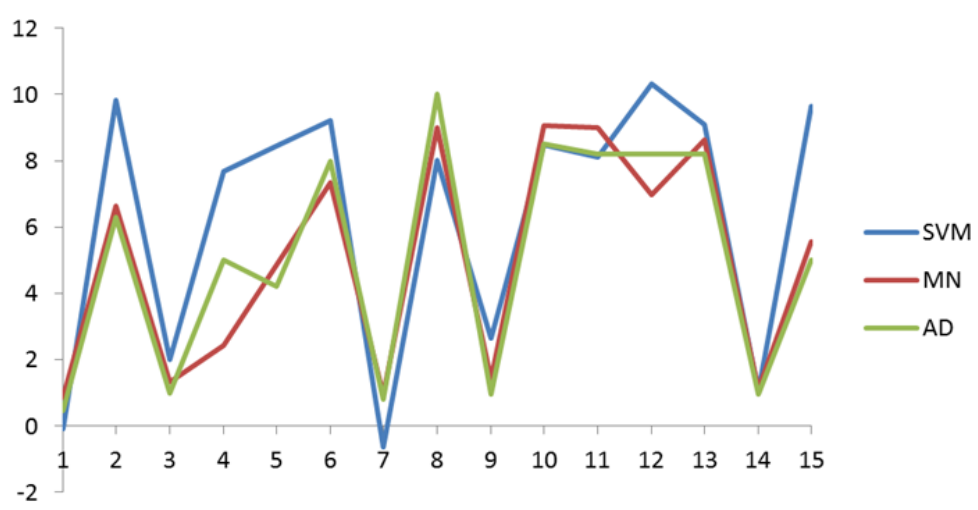

Figure 11. Predicted distances by modular network and support vector machine against actual distances (AD)

\subsection{Correlation and T-Test Results}

The distances from Al Ka'ba to point of interest predicted by modular network and support vector machine models are correlated in order find correlation between the two set of predicted values. The correlation between the two set of predicted distances is 0.836 as reported in Table 8 .

Table 8. Correlation between predicted values of modular network and support vector machine

\begin{tabular}{ccccc}
\hline & & N & Correlation & Sig. \\
\hline Pair 1 & SVM \& MN & 15 & 0.836 & 0.00 \\
\hline
\end{tabular}

Table 9. Paired sample test

\begin{tabular}{|c|c|c|c|c|c|c|c|c|}
\hline & & & \multicolumn{3}{|c|}{ Paired Differences } & \multirow{3}{*}{$\mathrm{t}$} & \multirow{3}{*}{ df } & \multirow{3}{*}{$\begin{array}{c}\text { Sig. } \\
(2 \text {-tailed })\end{array}$} \\
\hline & \multirow{2}{*}{\multicolumn{2}{|c|}{ Mean $\begin{array}{r}\text { Std. } \\
\text { Deviation }\end{array}$}} & \multirow{2}{*}{$\begin{array}{l}\text { Std. Error } \\
\text { Mean- }\end{array}$} & \multicolumn{2}{|c|}{$\begin{array}{r}95 \% \text { Confidence Interval of the } \\
\text { Difference }\end{array}$} & & & \\
\hline & & & & Lower & Upper & & & \\
\hline Pair 1 SVM- MN & 1.23940 & 2.18190 & 0.56336 & 0.03111 & 2.44770 & 2.200 & 14 & 0.045 \\
\hline
\end{tabular}

Table 9 reported results of t-test analysis conducted between values of distances predicted by modular network and support vector machine, each model predicted 15 values. Degree of freedom is $14,95 \%(0.05)$ confidence level, $t$ computed is 2.2 and critical value is 2.14 .

Table 10. Established Results of comparison between different neural networks architectures

\begin{tabular}{ll}
\hline Refs & \multicolumn{1}{c}{ Results } \\
\hline & Elman recurrent network perform better than feed forward neural \\
(Gencay \& Liu, 1997)) & network \\
(Cao \& Tay, 2001) & Support vector machine outperform Back propagation neural network \\
(Tay \& Cao, 2001) & Support vector machine outperform Back propagation neural network \\
(Kulkarni S., \& Haidar, I. (2009) & Multilayer feed forward network perform better than recurrent network \\
& Recurrent neural network perform better than time delay and \\
(Saad et al., 1998) & probabilistic neural networks \\
(Fernandez, 2012) & First case (neural network perform better than support vector machine), \\
& Second case (support vector machine outperform neural network) \\
(Quek et al., 2008) & Recurrent network perform better than multilayer perceptron and Elman \\
(Xie et al., 2008) & neural network \\
(Kaynar et al., 2010) & Support vector machine outperform Back propagation neural network \\
& Neuro-fuzzy inference system perform better than multilayer perceptron
\end{tabular}


(Zimberg, 2008)

(Qi \& Zhang, 2009)

(Yu et al 2008)

(Byvatov et al., 2003)

(Chen et al., 2001) and radial basis function network

Adaptive neuro-fuzzy inference system perform better than Elman neural network and feed forward neural network

Cluster support vector machine perform better than conventional support vector machine

First case (radial basis function network perform better than support vector machine and back propagation network), second case (support vector machine outperform radial basis function network and back propagation neural network)

Support vector machine outperform neural network

Support vector regression perform better than radial basis function network

\section{Discussion}

Performance measures listed in Table 7 indicated modular network and support vector machine perform very poor as $r$ between values predicted by support vector machine and actual values shows there is no correlation (see Figure 9). For modular network the $r$ value is very poor as well as MSE, NMSE and MAE for both models but the two compared results suggested modular network is the best of the worst. This signified very poor convergence for both models. Training results for modular network and support vector machine presented in Figures 9-10 and values of MSE for training and cross validation for both models suggested good convergence. It was found that difference between values of minimum and final training MSE varies a little bit so also minimum and final cross validation MSE, though not substantially. Values of cross validation MSE are better than training MSE. Generally, the training results suggested modular network training and cross validation MSE are superior to support vector machine training and cross validation MSE. Therefore, convergence of modular network is better than support vector machine. Figure 11 and Table 7 report a brief summary of basis to rely upon to take decision on performance effectiveness of our models. All the statistical indices listed in Table 7 measured prediction accuracy of modular network and support vector machine. MSE, NMSE, MAE and $\mathrm{r}$ clearly suggested that modular network perform better than support vector machine in predicting distances from $\mathrm{Al} \mathrm{Ka'ba} \mathrm{based} \mathrm{on} \mathrm{longitude} \mathrm{and} \mathrm{latitude} \mathrm{to}$ pilgrim's point of interest. A careful examination of Figure 11 further revealed correlation between distances predicted by both models and actual distances. The plot indicated patterns predicted by modular network is closer to actual distances than patterns predicted by support vector machine. Therefore, have better generalization capability. Values of MSE, NMSE, MAE and $\mathrm{r}$ for support vector machine indicated the model is also good in terms of generalization ability. Training, cross validation and test results shows performance of modular network is consistent. Generally, it was observed that prediction accuracy significantly improved with randomized data. Probably, is due to data randomization. Table 8 Shows correlation between values predicted by modular network and support vector machine is statistically significant. Table 9 reported results of t-test in which $\mathrm{H}_{0}$ is accepted and $\mathrm{H}_{1}$ rejected suggesting prediction accuracy of modular network is better than support vector machine but the difference is not statistically significant. Table 10 reported established results in literature. Different neural networks architectural configurations are used to built a model and prediction results generated by the models are compared to assessed performance accuracy. Previous comparison results as pointed out in Table 10 clearly showed no any single neural network architecture perform better in all cases. Probably is because of different problem domain in which the neural networks are applied. What is common among the literature is lack of check whether prediction performance among compared architectures is statistically significant or not. Correlation of values predicted between compared models is also lacking

\section{Conclusion}

This paper offer informative comparisons of modular network and support vector machine within the context of distance prediction from $\mathrm{Al} \mathrm{Ka'ba} \mathrm{to} \mathrm{point} \mathrm{of} \mathrm{interest} \mathrm{based} \mathrm{on} \mathrm{longitude} \mathrm{and} \mathrm{latitude.} \mathrm{Having} \mathrm{prior} \mathrm{approximate}$ distances within $\mathrm{Al} \mathrm{Haram} \mathrm{to} \mathrm{point} \mathrm{of} \mathrm{interest} \mathrm{can} \mathrm{enable} \mathrm{pilgrims} \mathrm{to} \mathrm{properly} \mathrm{plan} \mathrm{for} \mathrm{time} \mathrm{cost} \mathrm{when} \mathrm{the} \mathrm{needs} \mathrm{for}$ getting to a point of interest arise within Masjid Al-haram while performing Hajj and Umrah "the Muslim ritual". In addition, this also offers flexibility in making choices on places of interest within Al-haram and convenience in planning for many activities within Al-haram. Experimental investigation demonstrated that modular network applied in this research produce higher prediction accuracy than support vector machine. Correlation between the values predicted by both models is statistically significant but the difference in prediction accuracy between the two models is not statistically significant as revealed by the experimental results and analysis. This contribution May provide insight for researchers in choosing appropriate neural network architectural configuration for 
application in a particular problem domain. In a specific problem domain, it seems several neural network architectures (feed forward network, recurrent network and support vector machine) has to be experimentally tried since no particular architecture is superior to others in solving all types of problems. Therefore, searching for suitable and optimum neural network requires several architectures to be experimentally tried and adopt the best.

\section{Acknowledgments}

This research is supported by International Islamic University Malaysia (IIUM) Fundamental Research Grant Scheme through the Ministry of Higher Education Malaysia. The authors wish to thank Kulliyyah of Information and Communication Technology (KICT) IIUM for their kind assistance.

\section{References}

Abubakar, A. I., Mantoro, T., \& Mahmud, M. (2011). Exploring end-user preferences of $3 D$ mobile interactive navigation design. In Proceedings of the 9th International Conference on Advances in Mobile Computing and Multimedia (pp. 289-292). ACM.

Allison, D. (2005). MAPPRO: A program for processing the projection of latitude-longitude coordinates into rectangular map coordinate systems Original. Computers \& Geosciences, 21(7), 859-875.

Anand, R., Mehrotra, K., Chilukuri, K. M., \& Ranka, S. (2005). Efficient classification for multiclass problem using modular neural networks. IEEE Transactions on Neural Network, 6(1), 117-124.

Bishop, C. M. (2006). Pattern recognition and machine learning. Springer, Singapore.

Byvatov, E., Fechner, U. J., Sadowski, G., \& Schneider, U. (2003). Comparison of support vector machine and artificial neural networks for drug/Nondrug classification. Journal of Chemical Information and Computer Sciences, 43, 1882-1889.

Cao, L., \& Tay, F. E. H. (2001). Financial forecasting using support vector machines. Neural Computing, 10, 184-192.

Carcenac, M. (2008). A modular neural network applied to image transformation and mental images. Neural Computing \& Applications, 17, 549-568. http://dx.doi.org/10.1007/s00521-007-0152-4

Chen, S., Yu, P., \& Liu, B. (2011). Comparison of neural network architectures and inputs for radar rainfall adjustment for typhoon events. Journal of Hydrology, 405, 150-160.

Cho, S. (1997). Combining modular neural networks developed by evolutionary algorithms. In IEEE International Conference on Evolutionary Computation (IEEE-CEC), 647-650. http://dx.doi.org/10.1109/ICEC.1997.592393

Choi, H., \& Lee (2011). Motion Adaptive Deinterlacing with Modular Neural Networks. IEEE Transactions on Circuits and Systems for Video Technology, 21(6), 844-849.

Ericksen, D. E. (2007). National Association of Broadcasters Engineering Handbook (10th Edn), 89-93.

Fernandez, V. (2012). Forecasting crude oil and natural gas spot prices by classification methods. IDEAS. Retrieved June 4, 2006, from http://www.webmanager.cl/prontus_cea/cea_2006/site/asocfil e/ASOCFILE120061128105820.pdf

Friedman, R., Hefez, I., Kanza, Y., Levin, R., Safra, E., \& Sagiv, Y. (2012). WISER: a web-based interactive route search system for smartphones. In Proceedings of the 21st international conference companion on World Wide Web, 337-340.

Funand, M. H., \& Hagan, M. T. (1996). Modular neural networks for friction modeling and compensation. In Proceedings of the 1996 IEEE International Conference on Control Applications, 814-819.

Gencay, R., \& Liu, T. (1997). Nonlinear modeling and prediction with feed forward and recurrent networks. Physica D, 108, 11-134.

Gradojevic, N., Gençay, R., \& Kukolj, D. (2009). Option pricing with modular neural networks. IEEE Transactions on Neural Network, 20(4), 629-637.

Granitto, P. M., Verdes, P. F., \& Ceccatto, H. A. (2005). Neural network ensembles: evaluation of aggregation algorithms. Artificial Intelligence, 163, 139-162.

Grewal, M. S., Weill, L. R., \& Andrews, A. P. (2001). Global Positioning Systems, Inertial Navigation, and Integration. John Wiley and Sons, New York, USA. 416.

Guo, J. Y., \& Shum, C. K. (2009). Application of the cos-Fourier expansion to data transformation between 
different latitude-longitude. Computers \& Geosciences, 35(7), 1439-1444.

Ishikawa, M. (1995). Learning of modular structured networks. Artificial Intelligence, 75, 51-62.

Jacobs, R. A., \& Jordan, M. I. (1993). Learning piecewise control strategies in a modular neural network architecture. IEEE Transaction on System Man Cybernetics, 23(2), 337-345.

Jacobs, R. A., Jordan, M. I., \& Nowlan, S. J., \& Hinton, G. E. (1991). Adaptive mixtures of local experts. Neural Computing, 3, 79-87.

Kaplan, E., \& Hegarty, E. J. (2006). Understanding GPS: principles and applications (2nd Ed). Artech House, Norwood. USA. 576.

Kaynar, O., Tastan, S., \& Demirkoparan, F. (2010). Crude oil price forecasting with artificial neural networks. Ege. Acad. Rev., 10(2), 559-573.

Kessler, F. C. (2009). Projections. International Encyclopedia of Human Geography, 455-473.

Kulkarni S., \& Haidar, I. (2009). Forecasting model for crude oil price using artificial neural networks and commodity future prices. International Journal of Computer Science and Information Security, 2(1), 81-88.

Lopes, D. C., Magalhães, M. R. M., Melo, J. D., \& Dória, A. D. N. (2004). Implementation and Evaluation of Modular Neural Networks in a Multiple Processor System on Chip to Classify Electric Disturbance. In proceedings of IEEE International Conference on Computational Science and Engineering, 412-417.

Martinez, G., Melin, P., \& Castillo, O. (2005). Optimization of Modular Neural Networks Using Hierarchical Genetic Algorithms Applied to Speech Recognition. In Proceedings of International Joint Conference on Neural Networks (IJCNN), Montreal, Canada, 1400-1405.

Pavell, C. (2012). The walk distances in graphs. Discrete Applied Mathematics, 160(10-11), 1484-1500.

Qi, Y., \& Zhang, W. (2009). The improved SVM for forecasting the fluctuation of international crude oil prices. In Proceedings of IEEE International Conference on Electronic Commerce and Business Intelligence, 269-271.

Quek, C., Pasquier, M., \& Kumar, N. (2008). A novel recurrent neural network-based prediction system for option trading and hedging, Applied Intelligence, 29, 138-151.

Robusto, C. C. (1957). The Cosine-Haversine formula. The American Mathematics Monthly, 64, 38-40.

Saad, W. E., Prokhorov, V. D. C., \& Wunsch, C. D. (1998). Comparative Study of Stock Trend Prediction Using Time Delay, Recurrent and Probabilistic Neural Networks. IEEE Transactions on Neural Network, 9(6), 1456-1470.

Sharkey, N. E., Anderson, J. A., \& Rosenfeld, E. (2000). Talking Nets: An Oral History of Neural Networks. Artificial Intelligence, 119, 287-293.

Sheikhan, M., \& Ali, A. S. (2012). PSO-optimized modular neural network trained by OWO-HWO algorithm for fault location in analog circuits. Neural Computing \& Applications. http://dx.doi.org/ 10.1007/s00521-012-0947-9

Sinnott, R. W. (1984). Virtues of the Haversine. Sky and Telescope, 68 (2), 159.

Srivastava, V., Bipin, K. T., \& Vinay, K. P. (2012). Evolutionary fuzzy clustering and functional modular neural network-based human recognition. Neural Computing \& Applications. http://dx.doi.org/ 10.1007/s00521-012-0973-7

Tay, F. E. H., \& Cao, L. (2001). Application of support vector machines in financial time series forecasting. Omega, 29, 309-317.

Van Liere, D. (2010). How far does a tweet travel? Information brokers in the twitter verse. In Proceedings of the International Workshop on Modeling Social Media, Article No. 6 (2010).

Wang, E., Zhang, S., \& Zhang, Z. (2010). Research on the Incomplete Constellation GPS Positioning Algorithm by a Combined Altitude and Clock Bias Model. Proceedings of WASET International Conference on Information Engineering, 2, 219-222.

Xie, W., Yu, L., Xu, S., \& Wang, S. (2006). A new method for crude oil price forecasting based on support vector machines. Lecture Notes in Computer Science, 3994, 441-451.

Yu, L., Wang, S., \& Wen, B. (2008). An AI-agent trapezoidal fuzzy ensemble forecasting model for crude oil prediction. In Proceeding of the IEEE 3rd International Conference on Innovative Computing Information 
and Control, 327.

Zimberg, B. (2008). Crude oil price forecasting with ANFIS. University of Vaasa. Retrieved July 3, 2012, http://lipas.uwasa.fi/ phelo/ICIL2008TelAviv/24.pdf

\section{Notes}

Note 1. GPSVisualiza.com

\section{Copyrights}

Copyright for this article is retained by the author(s), with first publication rights granted to the journal.

This is an open-access article distributed under the terms and conditions of the Creative Commons Attribution license (http://creativecommons.org/licenses/by/3.0/). 